\title{
Concentration of amoxycillin and clavulanate in lung compartments in adults without pulmonary infection
}

\author{
P J Cook, J M Andrews, J Woodcock, R Wise, D Honeybourne
}

\begin{abstract}
Background - The efficacy of an antibiotic is usually predicted from serum levels and $\mathrm{MIC}_{90}$ values for likely pathogens, but in the lung tissue concentrations may be more informative. This study compares concentrations of amoxycillin and clavulanate in serum, epithelial lining fluid (ELF), alveolar macrophages, and bronchial mucosa in 15 adults.
\end{abstract}

Methods - Amoxycillin $500 \mathrm{mg}$ and clavulanic acid $250 \mathrm{mg}$ were given 1-2 hours before diagnostic bronchoscopy for haemoptysis or radiological abnormality. Mucosal biopsy samples were taken from macroscopically normal sites, alveolar macrophages harvested by lavage, and ELF volume derived from urea concentrations in bronchial lavage fluid and blood. Amoxycillin was assayed by inhibition of growth of Micrococcus lutea, and clavulanate (in serum, ELF, and bronchial mucosa) by inhibition of growth of Klebsiella pneumoniae; in macrophages clavulanate was measured by high performance liquid chromatography.

Results - The median concentrations in serum were $6.90 \mathrm{mg} / \mathrm{l}$ for amoxycillin and $5.25 \mathrm{mg} / 1$ for clavulanate. The median bronchial mucosal concentration of amoxycillin was $2.99 \mathrm{mg} / \mathrm{l}$ and of clavulanate was $1.65 \mathrm{mg} / 1$; the median concentrations in ELF were 0.89 and $0.96 \mathrm{mg} / 1$, and in macrophages 0 and $0.76 \mathrm{mg} / \mathrm{l}$, respectively. In macrophages amoxycillin levels were undetectable in 10 of 14 subjects (71\%); by contrast, only 6 of 14 subjects $(43 \%)$ had no detectable clavulanate.

Conclusions - Clavulanate levels exceeded quoted $\mathrm{MIC}_{90}$ values (around $0.25 \mathrm{mg} / \mathrm{l}$ ) for Legionella pneumophila both in ELF and in macrophages. Amoxycillin-clavulanate may therefore have a clinical role in infections with Legionella pneumophila.

(Thorax 1994;49:1134-1138)

During the last decade 20-32\% of Haemophilus influenzae serotype b and about $15 \%$ of nonencapsulated $H$ influenzae isolates have been resistant to ampicillin, mainly as a consequence of the non-inducible $\beta$-lactamase TEM-1. ${ }^{1} \mathrm{~A}$ similar increase in the production of $\beta$-lactamases has been observed, particularly in the hospital setting, among clinical isolates of several other organisms including enterobacteria (especially Escherichia coli), Moraxella catarrhalis, ${ }^{2}$ and some Gram positive cocci. ${ }^{3}$ These enzymes now provide the commonest mechanism of resistance to $\beta$-lactam antibiotics among clinical bacterial isolates. A number of $\beta$-lactam compounds, including the oxapenam clavulanic acid and the penicillanic sulphones tazobactam and sulbactam, inhibit a wide range of $\beta$-lactamases by binding to their active sites, thus increasing the efficacy of $\beta$-lactam antibiotics. Amoxycillin-clavulanate, a broad spectrum antibiotic comprising mixtures of clavulanic acid with the modified aminopenicillin amoxycillin is used in both lower and upper respiratory tract infections, ${ }^{4}$ particularly community acquired pneumonias and acute purulent exacerbations of chronic bronchitis or bronchiectasis. ${ }^{56}$

To be effective against respiratory tract pathogens an antibiotic must achieve bactericidal concentrations at sites of infection. The present study compares concentrations of amoxycillin and clavulanate in serum, bronchial mucosa, epithelial lining fluid (ELF), and alveolar macrophages in adults undergoing diagnostic bronchoscopy for chest radiographic abnormalities or haemoptysis.

\section{Methods}

PATIENTS

Fifteen patients (12 men and three postmenopausal women) were recruited into the study. These patients had a mean age of 58.7 years (range 24-75) and mean weight of $67.0 \mathrm{~kg}$ (range 47.2-97.0). None had significant renal or hepatic impairment and all were free of lung infection. Thirteen patients had abnormal chest radiographs; the remaining two presented with haemoptyses. Each gave informed consent before entry into the study, the protocol of which had been approved by the hospital ethical committee.

BRONCHOSCOPY

One to two hours before bronchoscopy each patient (having fasted for the previous eight hours) swallowed $750 \mathrm{mg}$ amoxycillin-clavulanate (comprising amoxycillin $500 \mathrm{mg}$ and clavulanic acid $250 \mathrm{mg}$ ) with $200 \mathrm{ml}$ water. A standard premedication of $600 \mu \mathrm{g}$ atropine was given by intramuscular injection 60 minutes before bronchoscopy, $4 \mathrm{ml}$ of $4 \%$ lignocaine by nebuliser 40 minutes later, and up to $5 \mathrm{mg}$ midazolam intravenously at the time of bronchoscopy. At that time up to $4 \mathrm{ml}$ of $4 \%$ lignocaine was administered to the pharynx and 
vocal cords and $6 \mathrm{ml}$ of $2 \%$ lignocaine to the carina and main bronchi.

All antibiotic assays, except those in the ELF, were performed on the day of bronchoscopy. Venous blood was collected before the administration of amoxycillin-clavulanate and at bronchoscopy, and centrifuged at $1500 \mathrm{~g}$ for 10 minutes at $4^{\circ} \mathrm{C}$.

Bronchoalveolar lavage (BAL) was performed in the right middle lobe or the lingula. The first $50 \mathrm{ml}$ of BAL fluid was discarded to avoid contamination with cells and secretions from the proximal airways, and the next three $50 \mathrm{ml}$ aliquots were collected into a Teflon container (thus preventing adherence of aspirated cells). Lavage time was reduced to a minimum to limit the concentration-dependent efflux of solutes into BAL fluid. The total leucocyte count was estimated immediately with an improved Neubauer haemocytometer. Within five minutes of lavage the pooled BAL fluid was centrifuged at $400 \mathrm{~g}$ for five minutes: the supernatant was then freeze dried and reconstituted in one tenth of the original volume of distilled water, making a tenfold concentration.

Assuming that urea is present at the same concentration in ELF and blood, the volume of ELF in bronchoalveolar lavage aspirate can be calculated from urea concentrations in BAL fluid and serum, ${ }^{7}$ and concentrations of antibiotics derived as follows:

$$
\begin{aligned}
& \text { VolELF }=\text { VolBAL } \times[\text { urea }] \text { BAL } /[\text { urea }] \text { ELF } \\
& =\text { VolBAL } \times[\text { urea }] \text { BAL } /[\text { urea }] \text { SERUM } \\
& {[\text { antibiotic }] E L F=[\text { antibiotic }] \text { BAL }} \\
& \times[\text { urea }] \text { SERUM } /[\text { urea }] \text { BAL }
\end{aligned}
$$

In health approximately $95 \%$ of cells in the alveoli are alveolar macrophages ${ }^{8}$ whose mean (SE) volume has previously been estimated ${ }^{9}$ by velocity gradient centrifugation ${ }^{10}$ at $2 \cdot 42(0.41) \mu 1 / 10^{6}$ cells. The total volume of macrophages in the BAL aspirate was calculated, assuming that the leucocyte count and macrophage count were equal, as follows:

$$
\begin{aligned}
& \mathrm{Vol}_{\mathrm{Mo}}=2 \cdot 42 \times 10^{-6} \times \text { leucocyte } \\
& \text { count per } \mathrm{ml} \times \text { VolBAL }
\end{aligned}
$$

The cell pellet was suspended in a measured volume of cold phosphate buffer $(\mathrm{pH} 7 \cdot 0)$ and homogenised by ultrasonication on ice before antimicrobial concentrations were assayed. Concentrations of antimicrobials in macrophages were therefore calculated from the formula:

$$
[\mathrm{A}]_{\mathrm{Mo}}=\frac{[\mathrm{A}]_{\mathrm{Mo}+\mathrm{pb}} \times \mathrm{Vol}_{\mathrm{Mo}+\mathrm{pb}}}{\mathrm{Vol}_{\mathrm{Mo}}}
$$

where $[\mathrm{A}]_{\mathrm{Mo}+\mathrm{pb}}$ is the concentration measured and $\mathrm{Vol}_{\mathrm{Mo}+\mathrm{pb}}$ is the volume of macrophages and buffer.

Superficial biopsy samples for antimicrobial assay were taken from macroscopically normal subcarinal sites - that is, without erythema, oedema, induration, or abnormal friability - before diagnostic biopsy samples. Visibly bloodstained specimens were discarded. The tissue was transferred immediately to a humidity chamber, weighed, and homogenised by ultrasonication in a known volume of phosphate buffer $(\mathrm{pH} 7 \cdot 0)$ on ice.

\section{MICROBIOLOGICAL ASSAYS}

Amoxycillin was measured by inhibition of growth in an overnight broth culture of Micrococcus lutea (ATCC 9341) diluted to an $\mathrm{OD}_{630}$ of 0.05 and poured over a $200 \mathrm{ml}$ No. 1 agar plate (Unipath, UK). Aliquots of all serum samples, concentrated ELF, mucosal tissue, and macrophages were placed in $5 \mathrm{~mm}$ wells cut in this agar and the plate was incubated for 24 hours at $37^{\circ} \mathrm{C}$. Zones of inhibition of bacterial growth around patient serum samples were compared with zones produced by standard amoxycillin concentrations in human serum ( $\mathrm{pH} \mathrm{7.0):} \mathrm{zones} \mathrm{around} \mathrm{mu-}$ cosal tissue and macrophage samples were compared with those produced by amoxycillin in phosphate buffer ( $\mathrm{pH} \mathrm{6.6).} \mathrm{For} \mathrm{assays} \mathrm{in}$ concentrated ELF standard amoxycillin preparations were made in $9 \%$ sodium chloride. The lower limit of sensitivity for these assays was $0.03 \mathrm{mg} / \mathrm{l}$.

Assay for clavulanic acid in serum, ELF, and mucosa was performed in a similar manner; $16 \mathrm{ml}$ of an overnight broth culture of Klebsiella pneumoniae (ATCC 29665), diluted to an $\mathrm{OD}_{630}$ of 0.8 , was incorporated into a $200 \mathrm{ml}$ No. 2 agar plate (Oxoid, Basingstoke, UK) containing piperacillin at a concentration of $80 \mathrm{mg} / \mathrm{l}$. Samples were incubated in $5 \mathrm{~mm}$ wells for 24 hours at $37^{\circ} \mathrm{C}$. As described above, zones of inhibition were compared with those produced by standard clavulanate concentrations in human serum ( $\mathrm{pH} \mathrm{7.0)}$ and 9\% sodium chloride. The lower limit of sensitivity for these assays was $0.02 \mathrm{mg} / \mathrm{l}$.

In these systems negative control preparations had no inhibitory effect on the assay organisms. The between assay coefficients of variation were $11 \cdot 4 \%$ for both assays.

HIGH PERFORMANCE LIQUID CHROMATOGRAPHY Clavulanic acid was assayed in alveolar macrophages by high performance liquid chromatography (HPLC), after reaction with imidazole, which produces a derivative absorbing at $311 \mathrm{~nm} .{ }^{112}$ The mobile phase was composed of $10 \mathrm{mM}$ disodium hydrogen orthophosphate (BDH), titrated to $\mathrm{pH} 2.5$ with orthophosphoric acid (BDH), $15 \mathrm{mM}$ octanesulphonic acid (BDH) as pairing ion, $23 \mathrm{mM}$ tetraethylammonium bromide (Sigma) as organic counter ion, and $5 \%$ acetonitrile (Rathburn Chemicals) passed through a $0.22 \mu \mathrm{m}$ filter: this was pumped at $0.4 \mathrm{ml} / \mathrm{min}$. All compounds were analytical grade or higher. $500 \mu \mathrm{l}$ of each alveolar macrophage homogenate or $500 \mu \mathrm{l}$ of phosphate buffer standard (pH 6.6) was mixed with $50 \mu \mathrm{l}$ imidazole (BDH $\geq 99 \%$ pure) in $5 \mathrm{M}$ hydrochloric acid (pH 6.8) and incubated in a light proof cabinet at room temperature for 60 minutes. $200 \mu$ of 
Table 1 Calculations of amoxycillin and clavulanic acid concentrations (in mg/l) in epithelial lining fluid

\begin{tabular}{|c|c|c|c|c|c|c|}
\hline Patient no & [Urea]SERUM & [Urea]BAL & {$[A \operatorname{mox}] 10 \times B A L$} & $\begin{array}{l}{[A \operatorname{Amox}] E L F} \\
=0 \cdot 1 \times[A] 10 \times \mathrm{BAL} \times[U] S E R U M /[U]_{B A L}\end{array}$ & {$[$ Clav] $10 \times B A L$} & 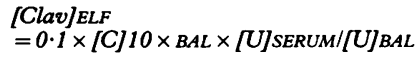 \\
\hline 1 & 6.5 & 0.028 & 0.15 & \multirow{15}{*}{ Unsuitable for processing } & $0 \cdot 36$ & $8 \cdot 36$ \\
\hline 2 & 3.7 & 0.035 & 0.08 & & $0 \cdot 10$ & 1.06 \\
\hline 3 & $7 \cdot 0$ & 0.035 & 0.06 & & $0 \cdot 11$ & $2 \cdot 20$ \\
\hline 4 & 5.5 & 0.060 & $0 \cdot 30$ & & 0.40 & 3.67 \\
\hline 5 & $6 \cdot 0$ & 0.080 & $0 \cdot 13$ & & 0.32 & $2 \cdot 40$ \\
\hline 6 & $3 \cdot 7$ & 0.014 & NDL & & NDL & 0 \\
\hline 7 & $7 \cdot 5$ & 0.036 & NDL & & NDL & 0 \\
\hline 8 & $3 \cdot 4$ & 0.016 & 0.07 & & 0.13 & $2 \cdot 70$ \\
\hline 9 & $4 \cdot 4$ & 0.029 & 0.06 & & 0.06 & 0.85 \\
\hline 10 & $9 \cdot 8$ & 0.036 & 0.02 & & 0.02 & 0.49 \\
\hline 11 & & & & & & \\
\hline 12 & 4.9 & 0.050 & 0.09 & & $0 \cdot 11$ & $1 \cdot 14$ \\
\hline 13 & $8 \cdot 1$ & 0.097 & NDL & & NDL & 0 \\
\hline 14 & 4.5 & 0.016 & NDL & & 0.05 & 1.08 \\
\hline 15 & $7 \cdot 1$ & 0.081 & NDL & & NDL & 0 \\
\hline
\end{tabular}

$\mathrm{NDL}=$ no detectable level.

Table 2 Concentrations (in mg/l) of amoxycillin and clavulanic acid in lung compartments

\begin{tabular}{|c|c|c|c|c|c|c|c|c|}
\hline \multirow[t]{2}{*}{ Patient no } & \multicolumn{2}{|l|}{ Serum } & \multicolumn{2}{|c|}{ Bronchial mucosa } & \multicolumn{2}{|c|}{ Epithelial lining fluid } & \multicolumn{2}{|c|}{ Alveolar macrophages } \\
\hline & [AmOx]SERUM & [Clav]SERUM & {$[A \operatorname{mox}] M U C$} & [Clav] MUC & {$[A \operatorname{mox}] E L F$} & [Clav]ELF & {$[A \operatorname{mox}] M o$} & [Clav]Mo \\
\hline $\begin{array}{r}1 \\
2 \\
3 \\
4 \\
5 \\
6 \\
7 \\
8 \\
9 \\
10 \\
11 \\
12 \\
13 \\
14 \\
15\end{array}$ & $\begin{array}{l}6 \cdot 50 \\
8 \cdot 60 \\
9 \cdot 80 \\
9 \cdot 50 \\
7 \cdot 20 \\
6 \cdot 60 \\
9 \cdot 00 \\
8 \cdot 20 \\
9 \cdot 10 \\
6 \cdot 90 \\
6 \cdot 00 \\
6 \cdot 60 \\
1 \cdot 70 \\
2 \cdot 20 \\
1 \cdot 20\end{array}$ & $\begin{array}{l}6 \cdot 50 \\
3 \cdot 65 \\
9 \cdot 45 \\
6 \cdot 50 \\
6 \cdot 60 \\
9 \cdot 95 \\
5 \cdot 25 \\
7 \cdot 30 \\
3 \cdot 40 \\
5 \cdot 40 \\
2 \cdot 30 \\
5 \cdot 20 \\
1 \cdot 75 \\
3 \cdot 10 \\
0.70\end{array}$ & $\begin{array}{l}3.84 \\
2.83 \\
2.99 \\
3.53 \\
3.36 \\
3.66 \\
3.57 \\
2.57 \\
3.30 \\
2 \cdot 70 \\
2.55 \\
3.51 \\
0.57 \\
0.05 \\
0.77\end{array}$ & $\begin{array}{l}3 \cdot 26 \\
1.24 \\
2 \cdot 99 \\
1 \cdot 77 \\
3 \cdot 73 \\
3 \cdot 26 \\
2 \cdot 50 \\
2 \cdot 38 \\
1 \cdot 10 \\
1 \cdot 20 \\
0 \cdot 89 \\
1 \cdot 65 \\
0 \cdot 57 \\
0 \cdot 04 \\
0 \cdot 46\end{array}$ & $\begin{array}{l}3.48 \\
0.85 \\
1.20 \\
2.75 \\
0.98 \\
0 \\
0 \\
1.50 \\
0.93 \\
0.55 \\
\\
0.98 \\
0 \\
0 \\
0\end{array}$ & $\begin{array}{l}8 \cdot 36 \\
1 \cdot 06 \\
2 \cdot 20 \\
3 \cdot 67 \\
2 \cdot 40 \\
0 \\
0 \\
0 \cdot 48 \\
0 \cdot 85 \\
0 \cdot 49 \\
\text { Lavage un } \\
1 \cdot 14 \\
0 \\
1 \cdot 08 \\
0\end{array}$ & $\begin{array}{l}0 \\
3 \cdot 18 \\
0 \\
1 \cdot 64 \\
0 \\
0 \\
0 \\
0 \\
0 \cdot 78 \\
0 \\
\text { for processin } \\
0 \\
0 \\
0 \\
0\end{array}$ & $\begin{array}{l}4 \cdot 28 \\
1 \cdot 03 \\
2 \cdot 58 \\
2 \cdot 74 \\
5 \cdot 81 \\
0 \\
0 \\
2 \cdot 70 \\
0 \cdot 49 \\
0 \\
\\
0 \\
0 \\
2 \cdot 90 \\
0\end{array}$ \\
\hline $\begin{array}{l}\text { No. } \\
\text { Median } \\
\text { Range }\end{array}$ & $\begin{array}{l}15 \\
6 \cdot 90 \\
8 \cdot 60\end{array}$ & $\begin{array}{l}15 \\
5 \cdot 25 \\
9 \cdot 25\end{array}$ & $\begin{array}{l}15 \\
2.99 \\
3.79\end{array}$ & $\begin{array}{l}15 \\
1.65 \\
3.69\end{array}$ & $\begin{array}{l}14 \\
0 \cdot 89 \\
3 \cdot 48\end{array}$ & $\begin{array}{l}14 \\
0.96 \\
8 \cdot 36\end{array}$ & $\begin{array}{l}14 \\
0 \\
3 \cdot 18\end{array}$ & $\begin{array}{l}14 \\
0 \cdot 76 \\
5 \cdot 81\end{array}$ \\
\hline
\end{tabular}

a $2 \mathrm{mg} / \mathrm{l}$ solution of salicylamide (Sigma) was added to provide an internal standard immediately before solid phase extraction. Extraction was carried out using $100 \mathrm{mg}(1 \mathrm{ml})$ C-18 Bond Elut cartridges (Varian), preconditioned with $1 \mathrm{ml}$ methanol, followed by $1.5 \mathrm{ml}$ water. Samples were added to the preconditioned cartridges which were then washed with $1.5 \mathrm{ml}$ water and allowed to dry. The adsorbed compounds (clavulanate derivative and salicylamide) were eluted into glass tubes with $500 \mu \mathrm{l}$ methanol, dried under a stream of air, and reconstituted in $50 \mu$ HPLC grade water by vortex mixing. $25 \mu \mathrm{l}$ of the eluate was then injected into a $\mathrm{C}_{18}$ Hypersil-ODS $(100 \times 2 \cdot 1 \mathrm{~mm}, 3 \mu \mathrm{m})$ reverse phase steel chromatographic column (HPLC Technology Ltd, UK). Samples were read with ultraviolet light at $311 \mathrm{~nm}$ using a Kontron 432 detector with an $8 \mu$ l flow cell.

In this system the amoxycillin does not interfere with the assay for clavulanic acid. Recovered salicylamide gave a coefficient of variation of $10.0 \%$ and clavulanate $12.5 \%$, with satisfactory resolution of the two compounds. The between-run coefficient of variation was $6.8 \%$ (at 0.25 and $0.1 \mathrm{mg} / \mathrm{l}$ ) and the lower limit of sensitivity was $0.0125 \mathrm{mg} / \mathrm{l}$.

\section{Results}

Table 1 shows the urea concentrations measured in BAL fluid and serum, assayed concentrations of amoxycillin and clavulanic acid in the lavage fluid ( $10 \times$ concentrated), and calculated ELF concentrations for each of the patients studied. The BAL fluid aspirated from one patient (no. 11) was unsuitable for analysis so that ELF and alveolar macrophage concentrations of these antibiotics could be determined in only 14 patients.

Table 2 shows concentrations of amoxycillin and clavulanic acid (in $\mathrm{mg} / \mathrm{l}$ ) measured in each lung compartment for each subject.

The calculation of mean values quoted takes account of those subjects in whom antibiotics were undetectable in one or more compartments; in macrophages, for example, amoxycillin levels were not detected in 11 of 14 subjects (79\%), while six of 14 subjects (43\%) had no detectable clavulanate.

\section{Discussion}

Methods for the measurement of total antibiotic concentrations in biopsy specimens are now well established. ${ }^{1314}$ The concentrations of antibiotics at the site of infection may be more informative than serum concentrations ${ }^{15}$ - for example, antibiotics may be concentrated in the urine and hence effective in urinary infections even where serum concentrations are so low as to predict clinical failure ${ }^{16}$ but renal tissue concentrations have been shown to be good predictors of efficacy in ascending urinary infections. ${ }^{1718}$ Differences between serum and tissue concentrations of antibiotics occur in discrete compartments of the lung (mucosa and submucosa, alveolar macrophages, epithelial lining fluid, and sputum). The alveolar membrane is thus relatively impermeable to antibiotics owing to the presence of many tight junctions (zonulae occludentes) $)^{19-21}$ and the 
capillary endothelium which separates the submucosa from blood, being non-fenestrated, ${ }^{223}$ is also less permeable than the fenestrated capillaries of other organs. ${ }^{24}$ Measured concentrations in each compartment depend on the rates of penetration and clearance: the lipophilicity, $\mathrm{pH}$, molecular weight, and protein binding of the drug also influence these processes. ${ }^{25}$

In acute bronchitis and acute exacerbations of chronic obstructive airways disease and bronchiectasis bacteria are found within the lumen of the airways, at the mucosal cell surface, and within bronchial mucosal tissue. ${ }^{26}$ In pneumonia they are also chiefly intraluminal: the ELF and alveolar macrophages appear to be important locations. ${ }^{27}$ These organisms are therefore separated from blood by significant barriers to antibiotic diffusion but, in some cases, antibiotics may be secreted into the bronchial lumen by epithelial cells. Measurement of antibiotic concentrations in sputum is technically difficult - for example, sputum is frequently contaminated by saliva into which antibiotics such as $\beta$-lactams penetrate only poorly, or by blood. ${ }^{28}$ Bronchial secretions collected by direct aspiration via an endotracheal tube or fibreoptic bronchoscope may have been pooling for some hours, allowing time for degradation by the $\beta$-lactamases of commensal bacteria; ${ }^{29}$ and concentrations of clavulanic acid, which is unstable at physiological temperatures, are particularly unreliable. ${ }^{30}$ Nevertheless the reported concentrations of $\beta$ lactams in directly harvested sputum samples are only $5-25 \%$ of serum levels. ${ }^{31}$ This may increase somewhat in the presence of active inflammation. By contrast, in all $\beta$-lactam antibiotics studied to date penetration into the bronchial mucosa is $35-50 \%{ }^{32} 33$ whether multiple or single dosing is used.

Bronchoalveolar lavage allows the measurement of antibiotic levels in ELF and alveolar macrophages, as well as in bronchial secretions, sputum, and lung tissue. ${ }^{34}{ }^{35}$ For practical purposes the ELF is defined as the fluid that lines the small airways distal to the point of impaction of the tip of the bronchoscope that is recovered by BAL. It is a complex mixture of solutes and anti-inflammatory cells, present in both healthy and infected people, bathing the terminal bronchioles, alveoli, and alveolar macrophages.

According to our data serum antibiotic concentrations show a partial correlation with those in bronchial mucosa, but not with ELF or macrophage levels. There is no reason, as far as we know, to expect a correlation between serum and macrophage concentrations, but in the case of ELF such a relationship might certainly be predicted. However, technical problems in processing BAL fluid cause a significant variation in antibiotic levels, particularly resulting from the movement of solute and solvent across the alveolar-capillary membrane. For example, vigorous suction during lavage promotes the efflux of urea into the aspirate, artificially increasing the estimated volume of ELF and thus depressing the derived drug concentrations; the antibiotics, especially clavulanic acid, are unstable at physiological temperatures. Despite the care that we have taken to standardise the procedures used in this study to keep dwell times to a minimum and to freeze dry all specimens (or store them at $-70^{\circ} \mathrm{C}$ ) before assay, we therefore believe that a correlation would always be difficult to demonstrate in ELF and macrophages.

However, the other drugs used during bronchoscopy (atropine, lignocaine and midazolam) are unlikely to have influenced the distribution or activity of the antibiotics. Atropine certainly reduces the volume of bronchial secretions but is not known to have any effect on ELF, while lignocaine, though exerting its pharmacological effects on cell membranes, has not been reported to alter antibiotic uptake by pulmonary tissues.

There is now considerable interest in the importance of intracellular infections in the lung with such pathogens as Legionella pneumophila, Chlamydia pneumoniae, and atypical mycobacteria, and in the special problems of antimicrobial delivery to these sites of infection. In such infections penetration of macrophages is an important property of antibiotics, but it is not clear whether this penetration occurs in the alveolar lumen, or whether circulating monocyte-derived macrophages acquire the drug before migrating to the alveolar compartment. Beta-lactams have generally been shown to be taken up only poorly by phagocytic cells compared with macrolides and quinolones. If particulate carriers such as liposomes and polyisohexylcyanoacrylate nanoparticles are used to transport $\beta$-lactam agents into macrophages, their bactericidal action is significantly enhanced: thus nanoparticle-bound ampicillin is more effective than free ampicillin against Listeria monocytogenes in mouse peritoneal macrophages. ${ }^{36}$ In infections with $\mathrm{Le}$ gionella pneumophila clavulanate and $\beta$-lactamclavulanate combinations are both bactericidal in vitro and in animal models. ${ }^{37}$ The present study indicates that, at least in some patients, clavulanate is taken up to a significant degree by bronchial mucosa, ELF, and macrophages, and exceeds quoted $\mathrm{MIC}_{90}$ values (around $0.25 \mathrm{mg} / \mathrm{l}$ ) for Legionella pneumophila ${ }^{3839}$ in these compartments. Its results are therefore consistent with those of the animal experiments mentioned above.

Interest in the treatment of Mycobacterium tuberculosis infection with $\beta$-lactam antibiotics has also been aroused recently by the discovery of an inducible, clavulanate-sensitive $\beta$-lactamase produced by this bacterium, active against penicillins and cephalosporins, and of a synergistic bactericidal effect of penicillinclavulanic acid combinations against $M$ tuberculosis. ${ }^{40}$

A potential clinical role for amoxycillinclavulanate in a variety of infections with intracellular pathogens is suggested. Further clinical studies to evaluate such a role may be warranted.

The help of Mr Nigel Brenwald, Ms Janet Ashby and other members of the Antimicrobial Chemotherapy Laboratory at Dudley Road Hospital is gratefully acknowledged. We are also grateful for the contribution
maceuticals in this study. 
1 Wenger JD, Hightower AW, Facklam RR, Gaventa S, Broome CV. Bacterial meningitis in the United States, 1986: report of a multistate surveillance study. $\mathcal{F}$ Infect $D i s$ 1990;162:1316-23.

2 Cunha BA. Amoxicillin/clavulanic acid therapy of respiratory tract infections: a microbiological perspective. Clin Ther 1992;14:418-25.

3 Pfaller M, Barry A, Fuchs P, Gerlach E, Hardy D, McLaughlin J. Relative efficacy of tazobactam, sulbactam and clavulanic acid in enhancing the potency of ampicillin against clinical isolates of Enterobacteriaceae. Eur f Clin Microbiol Infect Dis 1993;12:200-5.

4 Neu HC, Wilson AP, Gruneberg RN. Amoxicillin/clavulanic acid: a review of its efficacy in over 38,500 patients from acid: a review of its efficacy in over 38,500
1979 to 1992 . F Chemother 1993;5:67-93.

5 Legagni D, Lombardo VM, Negretto GG, Beghi G, Carato:zolo $O$. Comparative clinical and microbiological study of amoxicillin-clavulanic acid and ciprofloxacin in acute purulent exacerbations of chronic bronchitis. $\mathcal{F}$ Hosp Infect 1992;22(Suppl A):69-74

6 Brambilla C, Kastanakis S, Knight S, Cunningham K. Cefuroxime and cefuroxime axetil versus amoxicillin plus clavulanic acid in the treatment of lower respiratory tract infections. Eur f Clin Microbiol Infect Dis 1992;11:118-24.

7 Rennard SI, Basset G, Lecossier D, O'/donnell KM, Pinkston P, Martin G, et al. Estimation of volume of epithelial lining fluid recovered by lavage using urea as a marker of dilution. $\mathcal{f}$ Appl Physiol 1986;60:532-8.

8 Walters EH, Gardiner PV. Bronchoalveolar lavage as a Walters EH, Gardiner PV. Bronchoal
research tool. Thorax 1991;46:613-8.

9 Baldwin DR, Maxwell SRJ, Honeybourne D, Andrews JM, Ashby JP, Wise R. The penetration of cefpirome into the potential sites of pulmonary infection. $\mathcal{F}$ Antimicrob Chemother 1991;28:79-86.

10 Johnson JD, Hand WL, Francis JB, King-Thompson N, Corwin RW. Antibiotic uptake by alveolar macrophages. f Lab Clin Med 1980;95:429-39.

11 Foulstone M, Reading C. Assay of amoxicillin and clavulanic acid, the components of Augmentin, in biological fluids with high-performance liquid chromatography. Antimicrob with high-performance liquid chrom

12 Low AS, Taylor RB, Gould IM. Determination of clavulanic acid by a sensitive HPLC method. $\mathcal{F}$ Antimicrob Chemother acid by a sensitive HPLC

13 Honeybourne D, Andrews JM, Ashby JP, Lodwick R, Wise $R$. Evaluation of the penetration of ciprofloxacin and amoxicillin into the bronchial mucosa. Thorax 1988;43: 715-9.

14 Marlin GE, Braude PD, Whelan AJ, Somogyi AA. Penetration of enoxacin into human bronchial mucosa. $A m$ Rev Respir Dis 1986;134:1209-12.

15 Baldwin DR, Andrews JM, Ashby JP, Wise R, Honeybourne $D$. Concentrations of cefixime in bronchial mucosa and sputum after three oral multiple dose regimens. Thorax 1990;45:401-2.

16 Stamey TA, Fair WR, Timothy MM, Millar MA, Mihara $\mathrm{G}$, Lowery YC. Serum versus urinary antimicrobial concentrations in cure of urinary tract infections. $N$ Engl $\mathcal{f}$ 4;291:1159-63.

17 Fabre J, Rudhart M, Blanchard P, Reganey C. Persistence of sisomycin and gentamicin in renal cortex and medulla compared to other organs and serum in rats. Kidney Int 1976;10:444-9.

18 Glauser MP, Lyons JM, Braude AI. Prevention of pyelonephritis due to Escherichia coli in rats with gentamicin stored in kidney tissue. $\mathcal{F}$ Infect Dis 1979;139:172-7.

19 Taylor AE, Guyton AC, Bishop VS. Permeability of the alveolar membrane to solutes. Circ Res 1965;16:353-62.
20 Effros RM, Mason GR, Silverman P, Reid E, Hukkanen J. Movement of ions and small solutes across endothelium and epithelium of perfused rabbit lungs. $\mathcal{F}$ Appl Physiol 1986;60:100-7

21 Effros RM, Mason GR, Sietsema K, Hukkanen J, Silverman P. Pulmonary epithelial sieving of small solutes in rat lungs. $\mathcal{f}$ Appl Physiol 1988;65:640-8.

22 Staehelin LA. Structure and function of intracellular junctions. Int Rev Cytol 1974;39:191-283.

23 Weibel ER. The ultrastructure of the alveolar-capillary membrane or barrier. In: Fishman AP, Hecht $\mathrm{HH}$, eds. The pulmonary circulation and interstitial space. Chicago: Unipulmonary circulation and interstitial spac

24 Kaibara M, Kikkawa Y. Osmiophilia of the saturated phospholipid, dipalmitoyl lecithin, and its relationship to the alveolar lining layer of the mammalian lung. Am f Anat 1971;132:61-78.

25 Bergogne-Berezin E. Penetration of antibiotics into the respiratory tree. $\mathcal{F}$ Antimicrob Chemother 1981;8:171-4

26 Hers JFP, Mulder J. The mucosal epithelium of the respiratory tract in muco-purulent bronchitis caused by

Haemophilus influenzae. F Pathol Bacteriol 1953;66:103-8. Valcke Y, Pauwels R, van der Straeten M. Pharmacokinetic of antibiotics in the lungs. Eur Respir $f$ 1990;3:715-22.

28 Baldwin DR, Honeybourne D, Wise R. Pulmonary disposition of antimicrobial agents: methodological con-

Stockley RA, Dragicevic P, Burnett D, Hill SL. Role of $\beta$ lactamases in the response of pulmonary infections to lactamases in the response of pulmonary infections to
amoxicillin/clavulanate. $\mathcal{f}$ Antimicrob Chemother 1989; 42(Suppl B):73-81.

30 Gould IM, Legge JS, Reid TMS. Amoxicillin/clavulanic acid levels in lower respiratory secretions. $\mathcal{f}$ Antimicrob Chemother 1988;22:88-90.

31 Pennington JE. Penetration of antibiotics into respiratory secretions. Rev Infect Dis 1981;3:67-73.

32 Marlin GE, Burgess KR, Burgoyne J, Funnell GR, Guinness MDG. Penetration of piperacillin into bronchial mucosa and sputum. Thorax 1984;36:774-80.

33 Wise R, Baldwin DR, Honeybourne D, Andrews JM. Penetration of antibiotics into the bronchial mucosa - a review. Res Clin For 1990;12:95-100.

34 European Society of Pneumology Task Group on BAL. Technical recommendations and guidelines for bronchoalveolar lavage (BAL). Eur Respir f 1989;2:561-85.

35 BAL Co-operative Group Steering Committee. Bronchoalveolar lavage constituents in healthy individuals, idiopathic pulmonary fibrosis, and selected comparison groups. Am Rev Respir Dis 1990;141:S166-202.

36 Forestier F, Gerrier P, Chaumard C, Quero AM, Couvreur P, Labarre C. Effect of nanoparticle-bound ampicillin on the survival of Listeria monocytogenes in mouse peritoneal macrophages. F Antimicrob Chemother 1992;30:173-9.

37 Smith GM, Sutherland R. Activity of amoxicillin-clavulanic acid against Legionella pneumophila in vitro and in an experimental respiratory infection model. 7 Hosp Infect 1992;22(Suppl A):61-7.

38 Stokes DH, Slocombe B, Sutherland R. Bactericidal effects of amoxicillin/clavulanic acid against Legionella pneumophila. I Antimicrob Chemother 1989;23:43-51.

39 Smith GM, Abbott KH, Wilkinson MJ, Beale AS, Sutherland R. Bactericidal effects of ticarcillin-clavulanic acid against Legionella pneumophila pneumonia in immunocompromised patients. Antimicrob Agents Chemother 1991;35:1423-9.

40 Zhang Y, Steingrube VA, Wallace RJ. $\beta$-lactamase inhibitors and the inducibility of the $\beta$-lactamase of Mycobacterium tuberculosis. Am Rev Respir Dis 1992;145:657-60. 